\title{
Role of BCL2-associated athanogene in resistance to platinum-based chemotherapy in non-small-cell lung cancer
}

\author{
YADI WANG ${ }^{1}$, MINWEN HA ${ }^{2}$, JINGSONG LIU ${ }^{3},{\text { PING } \mathrm{LI}^{2} \text {, WENLU ZHANG }}^{2}$ and XUAN ZHANG ${ }^{2}$ \\ ${ }^{1}$ Department of Oncology, Third Affiliated Hospital of Liaoning Medical University; \\ ${ }^{2}$ Department of Oncology, First Affiliated Hospital of Liaoning Medical University; ${ }^{3}$ Department of Heart Surgery, \\ First Affiliated Hospital of Xuzhou Medical College, Jinzhou, Liaoning 121000, P.R. China
}

Received October 8, 2014; Accepted July 7, 2015

DOI: $10.3892 / \mathrm{ol} .2015 .4003$

\begin{abstract}
The present study aimed to address the pharmacogenetic role of BAG1 in platinum-based chemotherapy in advanced non-small-cell lung cancer (NSCLC) and in cultured human lung adenocarcinoma A549 cells. A total of 108 NSCLC patients (stages I-IIIA) were treated with a standard chemotherapy regimen of cisplatin plus vinorelbine. Additionally, in vitro cultured A549 cells were treated with cisplatin in the presence or absence of tunicamycin. Cell proliferation was determined by MTT assay and protein levels were assessed via western blot analysis. Patients with BAG1-positive expression were revealed to have a prolonged survival time (progression-free survival, 24.0 months) compared with that of patients without BAG1 expression (21.6 months; $\left.\chi^{2}=18.018, \mathrm{P}<0.05\right)$. Treatment of A549 cells with tunicamycin followed by cisplatin resulted in elevated BAG1 levels. In addition, tunicamycin was found to significantly enhance cisplatin-induced growth inhibition and apoptosis in A549 cells. The results indicate that BAG1 is important in cisplatin-induced cell death in lung adenocarcinoma, suggesting that endoplasmic reticulum stress may promote the sensitivity of NSCLC patients to chemotherapy.
\end{abstract}

\section{Introduction}

Non-small-cell lung cancer (NSCLC) is the leading cause of cancer-related mortality worldwide. At the time of diagnosis, the majority of patients are already in the advanced stages of inoperable disease $(1,2)$. Disease prevention, early

Correspondence to: Dr Minwen Ha, Department of Oncology, First Affiliated Hospital of Liaoning Medical University, 2 Renmin Street, Jinzhou, Liaoning 121000, P.R. China E-mail: haminwen2014@163.com

Abbreviations: BAG1, BCL2-associated athanogene; ER, endoplasmic reticulum; GRP78, glucose-regulated protein 78; KPS, karnofsky performance status; MTT, methyl thiazolyl tetrazolium; NSCLC, non-small cell lung cancer; NVB, vinorelbine

Key words: BCL2-associated athanogene, chemotherapy, cisplatin, non-small cell lung cancer diagnosis and cure rate have essentially remained unchanged during the past couple of decades, with a five-year survival rate for non-small cell lung cancer of 9-14\% (3). Although platinum-based chemotherapy is the first-line treatment for advanced NSCLC, the response rate is only $20-35 \%$, with a median survival time of $\sim 10$ months (4), indicating that a high proportion of advanced NSCLC patients are resistant to platinum-based chemotherapy. Accumulating evidence suggests that molecularly targeted therapies can individualize the treatment of NSCLC patients; however, these therapies depend upon the identification and validation of potent predictive biomarkers (2). Recent pharmacogenetic studies have demonstrated that individual variation in genetic background strongly influences the response of cancer patients to chemotherapy and radiotherapy $(5,6)$.

BCL2-associated athanogene-1 (BAG-1) is multifunctional protein that interacts with a wide range of cellular targets to regulate growth control pathways important for normal and malignant cells, including apoptosis, signaling, proliferation, transcription and cell motility. Of particular relevance to tumor cells, BAG-1 interacts with the anti-apoptotic BCL-2 protein, various nuclear hormone receptors and the $70 \mathrm{kDa}$ heat shock proteins, Hsc70 and Hsp70. Interaction with chaperones may account for many of the pleiotropic effects associated with BAG-1 overexpression (7). BAG-1 has also been identified as a multifunctional pro-survival protein $(8,9)$ that represses endoplasmic reticulum (ER) stress-induced apoptosis (10). BAG-1 can repress apoptosis induced by the stimulation of Fas and TRAIL death-receptors, kinase inhibitors, withdrawal of serum and cytokines from sensitive cells, heat shock, dexamethasone, radiation and anti-cancer agents, such as cisplatin and etopiside. Analysis of BAG-1 isoforms revealed that they all possess pro-survival activity. For example, previous studies have reported that inhibition of BAG1 expression prolongs the lifespan of NSCLC patients $(11,12)$. Although the activity of BAG-1 is predominantly cytoprotective, negative effects of BAG-1 on cell survival have also been described (9). Similarly, in a rodent model of NSCLC, reduced expression of BAG1 specifically promoted the apoptosis of tumor cells and delayed tumorigenesis (13).

The present study assessed the association between BAG1 expression levels and sensitivity to platinum-based chemotherapy in NSCLC patients. In addition, the involvement of 
BAG1-mediated ER stress in cisplatin-induced cell death was investigated using in vitro cultured human lung adenocarcinoma A549 cells.

\section{Patients and methods}

Patients. Between January 2009 and May 2010, 108 untreated patients with NSCLC [American Joint Committee on Cancer stages I-IIIA (14)] were recruited at the Department of Oncology of the First Affiliated Hospital of Liaoning Medical University (Jinzhou, China). All patients had a Karnofsky Performance Status score $(15)$ of $\geq 70$. The median age of the patients was 62 years (range, 43-81 years). Tumors were identified by cytological and histological examinations, with the tumor mass observed and measured by computed tomography or magnetic resonance imaging. Prior to chemotherapy, blood, liver and renal functions, and electrocardiogram results were within the normal range. The Ethics Committee of the First Affiliated Hospital of Liaoning Medical University approved the study protocol, and written informed consent was obtained from each participant.

Reagents. Tunicamycin was purchased from Sigma-Aldrich (St. Louis, MO, USA). Methyl thiazolyl tetrazolium (MTT) assay was purchased from BD Biosciences (Franklin Lakes, NJ, USA). Cisplatin was provided by Dezhou Deyao Pharmaceutical, Co., Ltd. (Dezhou, China). Cisplatin was obtained from China Otsuka Pharmaceutical Co., Ltd. (Tianjin, China). Vinorelbine (NVB) was obtained from Jiangsu Hansen Pharmaceutical Co., Ltd. (Lianyungang, China). RPMI-1640 culture medium was obtained from Gibco Life Technologies (Carlsbad, CA, USA). A polyclonal rabbit anti-mouse antibody against 3 isoforms of BAG1 [p50 (BAG1L), p46 (BAG1M) and p33 (BAG1S)] (cat. no. sc-939) was purchased from Santa Cruz Biotechnology, Inc. (Santa Cruz, CA, USA). Antibodies against procaspase-12 (rabbit anti-mouse polyclonal; cat. no. sc-5627), glucose-regulated protein 78 (GRP78; rabbit anti-human polyclonal; cat. no. sc-13968) and $\beta$-actin (mouse anti-avian monoclonal; cat. no. sc-47778) were purchased from Santa Cruz Biotechnology, Inc. The Annexin V-fluorescein isothiocyanate (FITC)/propidium iodide (PI) staining kit was obtained from Biouniquer Technology (Nanjing, China).

Chemotherapy and response evaluation. Day 1 was defined as the first day on which the chemotherapeutic agents were administered. Patients received a regular NVB+cisplatin regimen, with intravenous infusion of cisplatin $\left(30 \mathrm{mg} / \mathrm{m}^{2}\right)$ on days 2,3 , and 4 and NVB $\left(25 \mathrm{mg} / \mathrm{m}^{2}\right)$ on days 1 and 8 ; this was repeated every 3 weeks. The outcomes of chemotherapy were assessed according to the Response Evaluation Criteria in Solid Tumors (RECIST) (16) after four cycles. The overall responses to chemotherapy were classified as complete response, partial response, stable disease or progressive disease. Chemotherapy was considered efficacious if responses were complete or partial, whilst stable or progressive disease was defined as ineffective.

Immunohistochemistry. The expression of BAG1 in tumor tissues from patients was detected by immunohistochemistry. The $10 \%$ formalin-fixed and paraffin-embedded tissue sections were stained with anti-BAG1 antibodies at a dilution of 1:150. The immunoreactivity was visualized using an
SP immunohistochemistry staining kit, in accordance with the manufacturer's instructions (Beijing Zhongshan Golden Bridge Biotechnology, Co., Ltd., Beijing, China), and an IX70 inverted microscope (Olympus Corporation, Tokyo, Japan).

Therapeutic evaluation and survival analysis. Therapeutic effect was evaluated at two or three weeks following chemotherapy based on RECIST. The overall survival (OS) time of individual patients was defined from the day of surgery up until the final follow-up examination (July 31, 2012); median progression-free survival (PFS) and OS were plotted.

Cell culture. Human lung adenocarcinoma A549 cells were purchased from the Cell Bank of the Chinese Academy of Sciences (Shanghai, China). Cells were maintained in RPMI-1640 medium containing 10\% fetal bovine serum(NQBB International Biological Corporation, Guangzhou, China), and incubated in an atmosphere of $5 \% \mathrm{CO}_{2}$ in a humidified incubator (Sheldon Manufacturing, Inc., Cornelius, OR, USA) at $37^{\circ} \mathrm{C}$. Cells in logarithmic growth phase were used for experiments.

Evaluation of cell proliferation. To evaluate cell proliferation, an MTT assay was performed. A549 cells were seeded into a 96-well plate at a density of $6 \times 10^{3}$ cells/well. At $24 \mathrm{~h}$ after seeding, cells were treated with various concentrations of tunicamycin $(1.25-10 \mu \mathrm{g} / \mathrm{ml})$ for $8 \mathrm{~h}$. For combined treatment, cells were treated with $1.25 \mu \mathrm{g} / \mathrm{ml}$ tunicamycin for $8 \mathrm{~h}$ followed by $24 \mathrm{~h}$ of cisplatin treatment $(1.25-40 \mu \mathrm{g} / \mathrm{ml})$. Cells without drug treatment were used as the negative control. Five wells were examined for each group.

Subsequent to the chemotherapeutic treatments, $20 \mu 1$ MTT solution $(5 \mathrm{mg} / \mathrm{ml})$ was added to each well. Following $4 \mathrm{~h}$ of incubation at $37^{\circ} \mathrm{C}$, the medium was removed and $200 \mu$ l dimethyl sulfoxide (MP Biomedicals, LCC, Santa Ana, CA, USA) was added to each well to resuspend the MTT metabolic product. The absorbance of the dissolved formazan was measured at $492 \mathrm{~nm}$ (A492) using a microplate spectrophotometer (Model 500, Bio-Rad Laboratories, Inc., Hercules, CA, USA). The rate of growth inhibition was determined using the following formula: Growth inhibition rate $(\%)=\left(1-\left[\mathrm{A} 492_{\text {Sample }} / \mathrm{A} 492_{\text {Control }}\right] \times 100 \%\right.$. The half maximal inhibitory concentration $\left(\mathrm{IC}_{50}\right)$ was calculated using SPSS 17.0 software (SPSS, Inc., Chicago, IL, USA).

Determination of cell apoptosis. Cell apoptosis was determined via flow cytometric analysis. Briefly, cells were treated with $1.25 \mu \mathrm{g} / \mathrm{ml}$ tunicamycin for $8 \mathrm{~h}$ followed by a 24-h incubation with cisplatin $(1.25,2.5$, or $40 \mu \mathrm{g} / \mathrm{ml})$. Cells were collected by centrifugation (100 $\mathrm{x}$ g for $5 \mathrm{~min}$ at $4^{\circ} \mathrm{C}$ ) and (1-5) $\mathrm{x} 10^{5}$ cells were resuspended in Annexin V Binding Buffer. Subsequently, $5 \mu \mathrm{l}$ Annexin V-FITC and $5 \mu \mathrm{l}$ PI were added to the cell suspension and incubated at room temperature for $10 \mathrm{~min}$ in the dark. Apoptosis was analyzed by flow cytometry (BD FACSVerse ${ }^{\mathrm{TM}}$; BD Biosciences).

Western blot analysis. Following the drug treatments, cells were washed with ice-cold phosphate-buffered saline and incubated with radioimmunoprecipitation assay buffer (Beijing BLKW Biotechnology Co., Ltd., Beijing, China). The protein was collected and the protein concentration was 
Table I. Correlation between BAG1 chemosensitivity and clinicopathological features of non-small-cell lung cancer patients (n=108).

\begin{tabular}{|c|c|c|c|c|}
\hline \multirow[b]{2}{*}{ Features } & \multicolumn{2}{|c|}{ BAG1, n } & \multirow[b]{2}{*}{$\chi^{2}$} & \multirow[b]{2}{*}{ P-value } \\
\hline & Positive & Negative & & \\
\hline Gender & & & 0.462 & 0.497 \\
\hline Male & 47 & 9 & & \\
\hline Female & 41 & 11 & & \\
\hline Age, years & & & 2.681 & 0.102 \\
\hline$<60$ & 57 & 9 & & \\
\hline$\geq 60$ & 31 & 11 & & \\
\hline Smoking history & & & 3.377 & 0.066 \\
\hline Yes & 32 & 10 & & \\
\hline No & 56 & 10 & & \\
\hline Pathology & & & 0.022 & 0.882 \\
\hline Squamous-cell carcinoma & 38 & 9 & & \\
\hline Adenocarcinoma & 50 & 11 & & \\
\hline Tumor differentiation & & & 6.376 & 0.041 \\
\hline High & 38 & 4 & & \\
\hline Medium & 23 & 4 & & \\
\hline Low & 27 & 2 & & \\
\hline Tumor stage & & & 0.700 & 0.705 \\
\hline I & 35 & 6 & & \\
\hline II & 28 & 7 & & \\
\hline IIIa & 25 & 7 & & \\
\hline Lymph node metastasis & & & 1.608 & 0.205 \\
\hline Present & 39 & 12 & & \\
\hline Absent & 49 & 8 & & \\
\hline
\end{tabular}

BAG1, BCL2-associated athanogene.

Table II. Survival analysis in non-small-cell lung cancer patients by Cox proportional hazards model.

\begin{tabular}{lccrr}
\hline Features & F & Hazard ratio & Wald & P-value \\
\hline Gender & 1 & 0.214 & 1.008 & 0.315 \\
Pathological types & 1 & 0.391 & 2.865 & 0.090 \\
Differentiation stage & 1 & 1.603 & 27.449 & $<0.001$ \\
Clinical stage & 1 & 1.834 & 28.550 & $<0.001$ \\
Node metastasis & 1 & 0.517 & 1.833 & 1.677 \\
BAG1-positive & 1 & 2.359 & 41.663 & $<0.001$ \\
\hline
\end{tabular}

BAG1, BCL2-associated athanogene.

determined by Lowry assay (17). The total cell protein was resolved by $15 \%$ sodium dodecyl sulfate-polyacrylamide gel electrophoresis and transferred to a nitrocellulose membrane (eBioscience, Inc., San Diego, CA, USA). Membranes were blocked with $5 \%$ non-fat milk for $1 \mathrm{~h}$ at room temperature, followed by incubation with primary antibodies against BAG1 (BAG1L, BAG1M and BAG1S; dilution, 1:500), GRP78 (dilution, 1:500), procaspase-12 (dilution, 1:500) or $\beta$-actin (dilution, 1:200) overnight at $4^{\circ} \mathrm{C}$. After washing three times with Tris-buffered saline containing $0.1 \%$ Tween, membranes were probed with horseradish peroxidase-conjugated secondary antibody (monoclonal mouse anti-rabbit; cat. no. sc-51625; dilution, 1:800; Santa Cruz Biotechnology, Inc.) at $37^{\circ} \mathrm{C}$ for $30 \mathrm{~min}$. Proteins were detected using an electrochemiluminescence assay (Shanghai Rong Wei Industrial Co., Ltd.,Shanghai, China). 
A
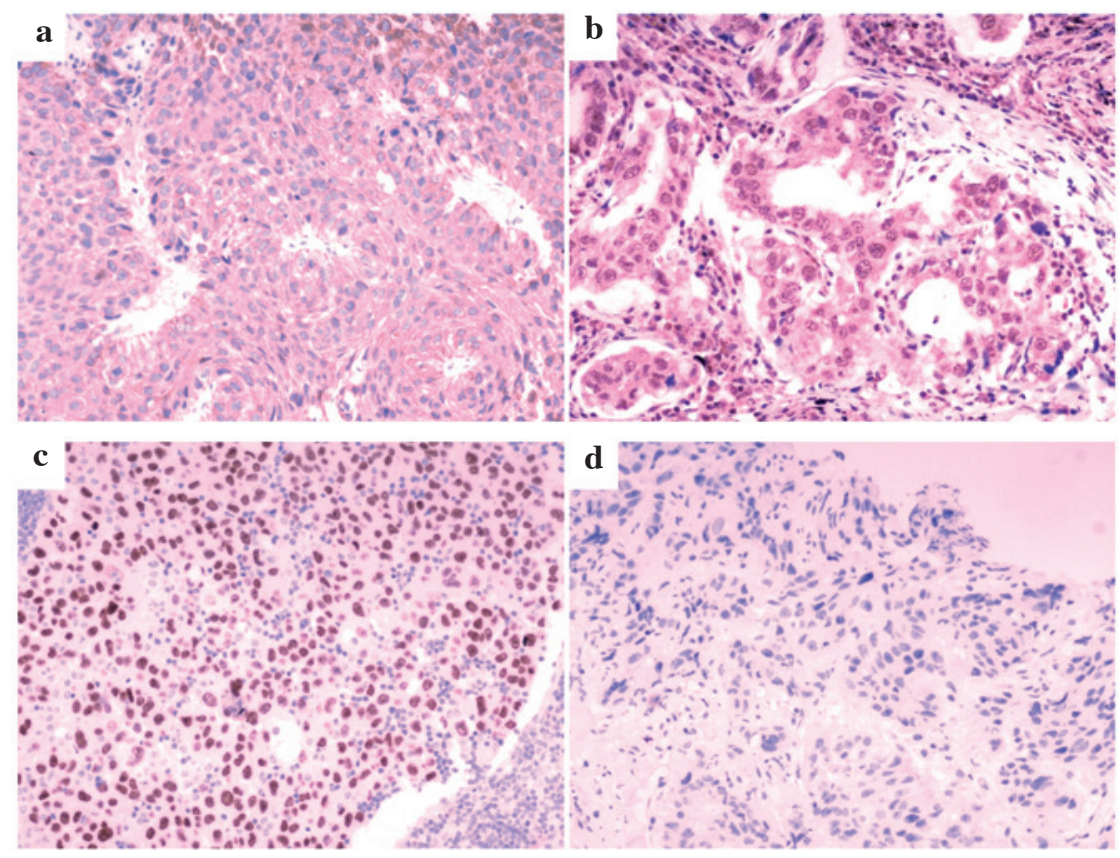

B a

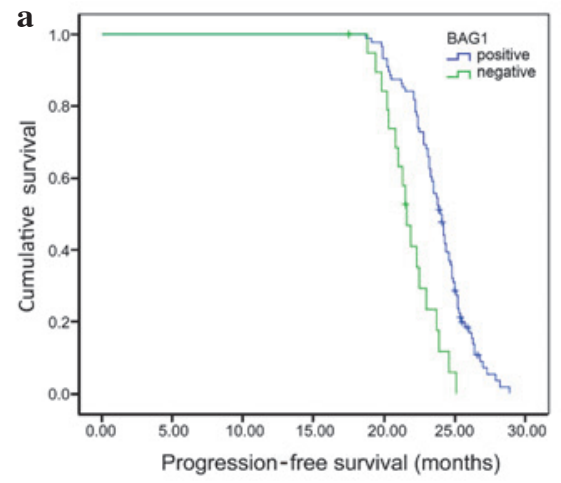

b

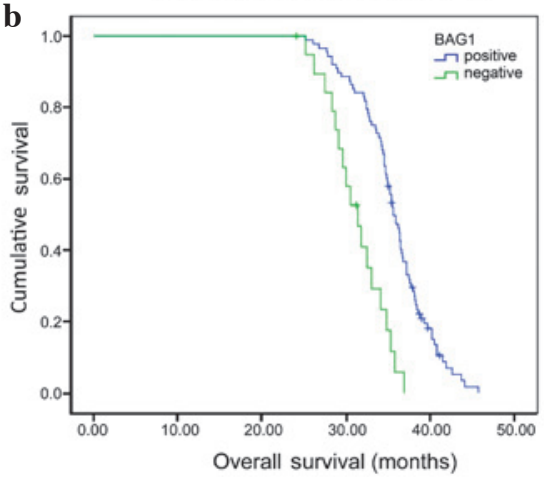

Figure 1. (A) Immunohistochemical analysis revealed cytosolic and nuclear expression of BAG1 in lung tissues of NSCLC patients: (a) Cytoplasmic expression of BAG1; (b) cytoplasmic and nuclear expression of BAG1; (c) nuclear expression of BAG1; and (d) negative control (magnification, x400). (B) Survival curves of patients: (a) time to progression of NSCLC patients with BAG-positive or -negative expression $\left(\chi^{2}=18.018, \mathrm{P}<0.001\right)$; and (b) overall survival of NSCLC patients with BAG-positive or -negative expression $\left(\chi^{2}=24.057, \mathrm{P}<0.001\right)$. BAG1, BCL2-associated athanogene; NSCLC, non-small-cell lung cancer.
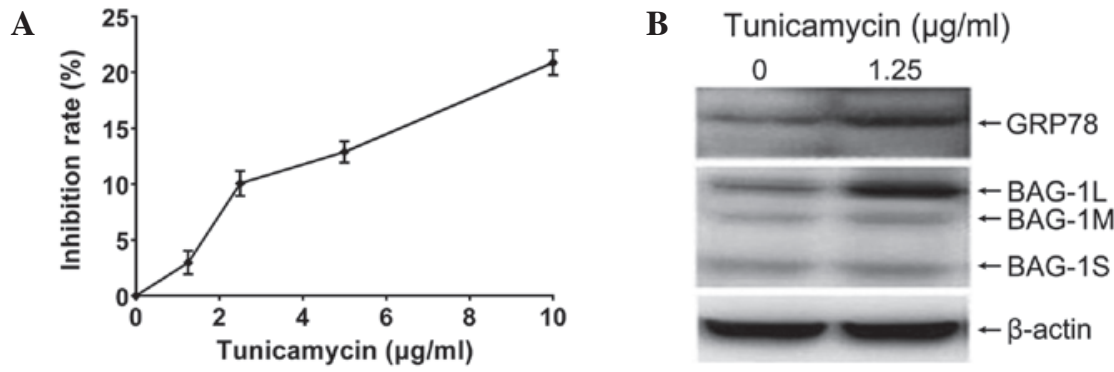

Figure 2. Tunicamycin-induced endoplasmic reticulum stress in A549 cells. (A) Effects of tunicamycin on the growth of A549 cells. Growth inhibition of A549 cells was examined using MTT assay. Data are presented as the mean \pm standard deviation from experiments conducted in triplicate. (B) Impact of tunicamycin on GRP78 and BAG1. A549 cells were treated with $1.25 \mu \mathrm{g} / \mathrm{ml}$ of tunicamycin for $8 \mathrm{~h}$, followed by immunoblot using the indicated antibodies. GRP78, glucose regulated protein 78; BAG1, BCL2-associated athanogene; L, p50 isoform; M, p46 isoform; S, p33 isoform.

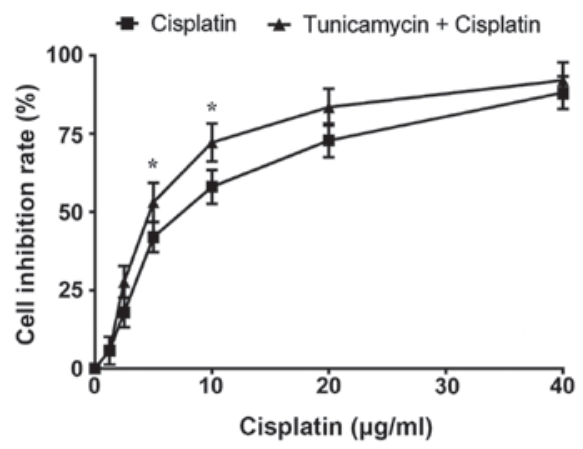

Figure 3. Tunicamycin enhanced the cell growth inhibition of A549 cells induced by cisplatin treatment. A549 cells were treated with cisplatin in the presence or absence of $1.25 \mu \mathrm{g} / \mathrm{ml}$ of tunicamycin for $24 \mathrm{~h}$ and cell viability was measured using MTT assay. Data are presented as the mean \pm standard deviation from experiments performed in triplicate. ${ }^{*} \mathrm{P}<0.05$ vs. treatment without tunicamycin.
Statistical analyses. Statistical analyses were performed using SPSS 17.0 software. Comparisons between two groups of subjects were made using the $\chi^{2}$ test. Survival rate was calculated through Kaplan-Meier analysis. Differences between factors were evaluated by log-rank test and a Cox regression analysis was used for determining prognostic factors. Data calculated from three independent experiments were presented as the mean \pm standard deviation and a Student's $t$-test was performed to compare two groups. $\mathrm{P}<0.05$ was considered to indicate a statistically significant difference.

\section{Results}

BAGl expression is associated with differentiation stage. The potential correlation between BAG1 expression and clinicopathological characteristics of NSCLC patients was 
A
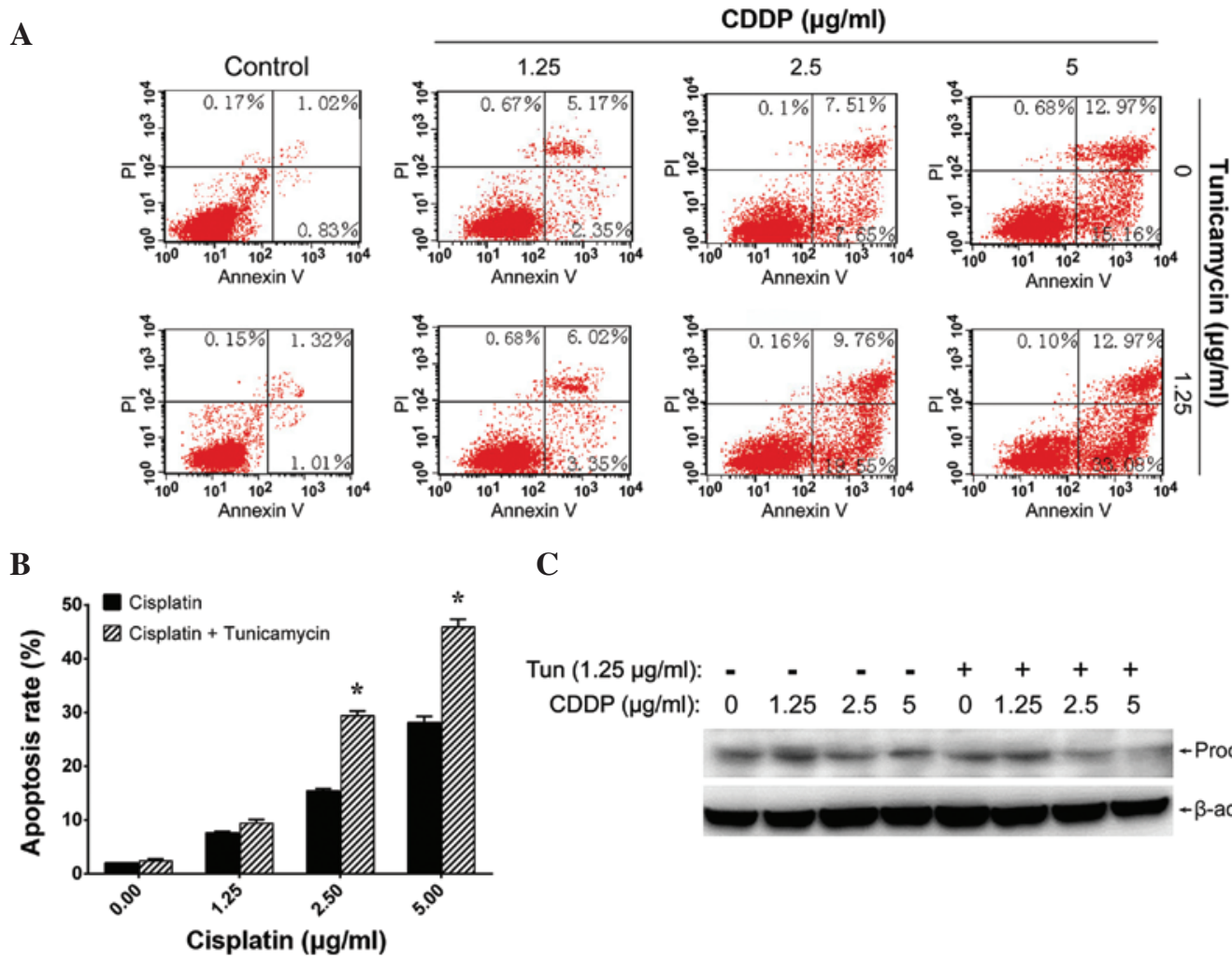

C
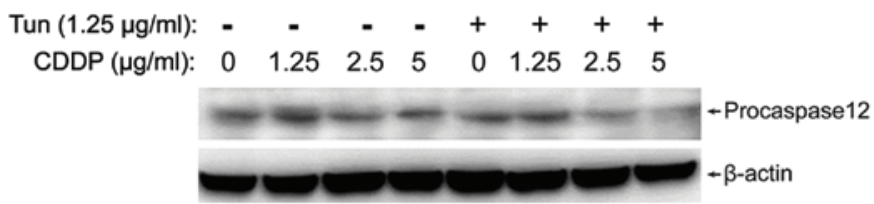

Figure 4. Tunicamycin enhanced cisplatin-induced apoptosis. A549 cells were treated with cisplatin in the presence or absence of $1.25 \mu \mathrm{g} / \mathrm{ml}$ tunicamycin for $8 \mathrm{~h}$. Apoptotic cells were analyzed using Annexin V-PI dual staining and quantified using flow cytometry. (A) Representative images of flow cytometric analysis. (B) Quantification of flow cytometry; data are presented as the mean \pm standard deviation from experiments performed in triplicate. ${ }^{*} \mathrm{P}<0.05$ vs. treatment without tunicamycin. (C) A549 cells were treated with cisplatin in the presence or absence of $1.25 \mu \mathrm{g} / \mathrm{ml}$ tunicamycin and lysates were subjected to immunoblotting analysis with indicated antibodies. CDDP, cisplatin; PI, propidum iodide; Tun, tunicamycin.

evaluated. The results indicated that expression of BAG1 was closely associated with differentiation stage, as BAG1 expression was higher in patients with moderate/high differentiation compared with that of patients with poorly differentiated tumors ( $\mathrm{P}=0.041$; Table I, Fig. 1A). However, no significant difference in BAG1 expression was identified based on gender, age, pathological type, clinical stage or lymph node metastasis status $(\mathrm{P}>0.05$, Table I).

BAG1-positive expression is associated with prolonged survival. A multivariate analysis (Cox regression model) was used to quantify the associations between prognostic factors and survival time in NSCLC patients. Differentiation stage, clinical stage and positive BAG1 expression were identified as independent prognostic factors for survival in patients with NSCLC ( $\mathrm{P}<0.05$; Table II). A life-table analysis revealed that the median PFS of NSCLC patients with BAG1-negative expression was 21.6 months. By contrast, the median PFS of NSCLC patients with BAG1-positive expression was markedly increased (PFS, 24.0 months; $\chi^{2}=18.018, P<0.001 ;$ Fig. 1Ba). In addition, OS times (calculated from the day of surgery to the final follow-up examination) and the results of the life-table analysis revealed that the median OS time of NSCLC patients with BAG1-negative expression (20 cases) was 31.4 months and the 3-year survival rate was $8.69 \%$. By contrast, the median OS time and rate of NSCLC patients with BAG1-positive expression (88 cases) were markedly increased (OS, 35.6 months; $\chi^{2}=24.057, \mathrm{P}<0.001$; Fig. $1 \mathrm{Bb}$ ) and the 3 -year survival rate was

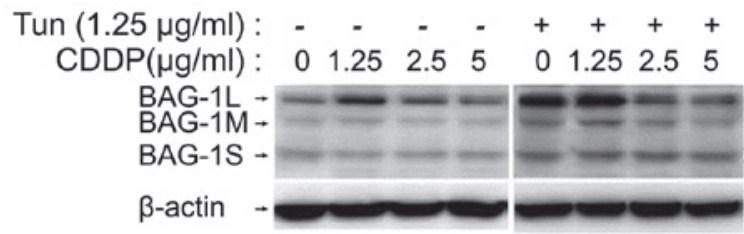

Figure 5. Impacts of endoplasmic reticulum stress on BAG1 induced by cisplatin treatment. A549 cells were treated with cisplatin in the presence or absence of $1.25 \mu \mathrm{g} / \mathrm{ml}$ tunicamycin. Cell lysates were subjected to immunoblot analysis with indicated antibodies. Tun, tunicamycin; CDDP, cisplatin; BAG1, BCL2-associated athanogene; L, p50 isoform; M, p46 isoform; S, p33 isoform.

$14.73 \%$. Collectively, these results suggest that the positive expression of BAG1 is associated with prolonged survival.

Tunicamycin induces ER stress and upregulation of BAGIL in A549 cells. Clinical data from the present study revealed that NSCLC patients with BAG1-positive expression responded more favorably to platinum-based chemotherapies. BAG1 is involved in ER stress (10), and tunicamycin has been demonstrated to induce ER stress (18). To elucidate the molecular mechanism by which NSCLC patients with decreased expression of BAG1 become resistant to platinum-based chemotherapies, tunicamycin was used to induce ER stress and the effects of tunicamycin and cisplatin in cultured human lung adenocarcinoma A549 cells were investigated. Incubation with tunicamycin for $8 \mathrm{~h}$ inhibited the proliferation of A549 cells in 
a dose-dependent manner (Fig. 2A). As $1.25 \mu \mathrm{g} / \mathrm{ml}$ tunicamycin induced $\sim 3 \%$ growth inhibition, this dose of tunicamycin was used for studying ER stress. The ER molecular chaperone, GRP78, was upregulated after $8 \mathrm{~h}$ of treatment with $1.25 \mu \mathrm{g} / \mathrm{ml}$ tunicamycin, indicating that tunicamycin evoked ER stress in A549 cells (Fig. 2B). Furthermore, protein levels of the BAG1L (p50) subtype were markedly elevated, whilst marginal increases in the BAG1M (p46) and BAG1S (p33) subtypes were observed following tunicamycin treatment. Thus, tunicamycin induces ER stress and upregulates BAG1L in A549 cells.

Tunicamycin enhances cisplatin-induced growth inhibition and apoptosis in A549 cells. The viability of A549 cells following treatment with tunicamycin plus cisplatin were assessed. Specifically, incubation with $1.25 \mu \mathrm{g} / \mathrm{ml}$ tunicamycin for $8 \mathrm{~h}$ followed by $24 \mathrm{~h}$ with cisplatin significantly enhanced the growth inhibition rate in A549 cells (Fig. 3): The combined treatment markedly decreased the $\mathrm{IC}_{50}$ value compared with that of cisplatin alone $(6.11 \pm 1.27 \mu \mathrm{g} / \mathrm{ml}$ vs. $8.53 \pm 1.68 \mu \mathrm{g} / \mathrm{ml}$; $\mathrm{P}<0.05)$. In addition, Annexin V-FITC/PI staining and flow cytometric analysis revealed that tunicamycin enhanced the cisplatin-induced apoptosis of A549 cells (Fig. 4A and B).

As ER stress may trigger apoptosis through the activation of caspase-12 (19), procaspase-12 levels were also monitored in A549 cells following different treatments. Treatment with $1.25 \mu \mathrm{g} / \mathrm{ml}$ tunicamycin for $8 \mathrm{~h}$ plus an additional 24-h incubation with 2.5 or $5 \mu \mathrm{g} / \mathrm{ml}$ cisplatin significantly downregulated procaspase-12 levels (Fig. 4C), indicating the activation of caspase-12. These results suggest that tunicamycin may enhance the effects of cisplatin in cultured lung adenocarcinoma cells.

Impacts of ER stress on BAG1 induced by cisplatin treatment. The protein levels of BAG1 were assessed by western blot analysis following treatment of A549 cells with the chemotherapeutic drugs cisplatin, tunicamycin or a combination of the two. Administration of cisplatin alone $(1.25,2.5$ or $5 \mu \mathrm{g} / \mathrm{ml})$ markedly elevated the level of BAG1L compared with that of the control group; a dose of $1.25 \mu \mathrm{g} / \mathrm{ml}$ was found to exert the maximal effect on BAG1L levels (Fig. 5). Treatment with $1.25 \mu \mathrm{g} / \mathrm{ml}$ tunicamycin for $8 \mathrm{~h}$ also enhanced BAG1L protein levels in A549 cells. Furthermore, incubation with tunicamycin $(1.25 \mu \mathrm{g} / \mathrm{ml})$ for $8 \mathrm{~h}$ plus $24 \mathrm{~h}$ of cisplatin treatment $(1.25 \mu \mathrm{g} / \mathrm{ml})$ further increased BAG1L expression compared with that observed in cells treated with tunicamycin alone. Similar results were observed for BAG1M. With regard to BAG1S, enhanced expression was detected after tunicamycin or tunicamycin plus cisplatin treatment, while marked differences were observed among different dose groups. These results suggest that both ER stress and DNA damage responses lead to the upregulation of BAG1 in A549 cells.

\section{Discussion}

Although platinum-based chemotherapy is the first-line treatment option for advanced NSCLC patients (2), patients with clinically similar characteristics respond variably (20). Inter-individual differences in genetic background have been demonstrated to affect the response to chemotherapy and OS rate of NSCLC patients receiving platinum-based chemotherapy (21-25). BAG1 is important in the development and progression of NSCLC $(11,12)$; however, the association between expression levels of BAG1 and the sensitivity of NSCLC patients to platinum-based chemotherapy remains to be determined.

The present study revealed that BAG1 expression was associated with the degree of differentiation of NSCLCs, but not with other clinicopathological characteristics, such as gender, age, pathological types, clinical stage or lymph node metastasis status (Table I). This suggests that BAG1 may be involved in the progression of NSCLC and contribute to disease development. The Cox multivariate analysis revealed that degree of differentiation, clinical stage and BAG1 expression were independent prognostic factors for survival in patients with NSCLC (Table II). Compared with patients with BAG1-negative expression, the median PFS time and survival rate of NSCLC patients with BAG1-positive expression were significantly higher (PFS, 21.6 vs. 24.0 months; $\left.\chi^{2}=18.018, \mathrm{P}<0.001\right)$. These results indicate that BAG1 may sensitize NSCLC cells to chemotherapy and could serve as an independent prognostic factor in NSCLC. However, the association between BAG1 expression and survival of patients with lung cancer is controversial: A recent study reported that the survival curves of the BAG1 low-expression group were favorable compared with those of the BAG1 high-expression group in lung cancer patients of TNM stage I (26). This discrepancy may be due to the different types of lung cancer studied.

It has been reported that BAG1 contributes to the induction of ER stress in chondrocytes (10). Consistent with this observation, the present study revealed that tunicamycin induced-ER stress was accompanied by an upregulation of BAG1 and GRP78 in A549 cells. In addition, the enhancement of ER stress induced by tunicamycin significantly increased cell growth inhibition and apoptosis in cisplatin-treated A549 cells. Activation of caspase-12 (i.e., reduced procaspase-12), a component of an ER stress-specific caspase cascade in apoptosis $(27,28)$, was detected following tunicamycin and cisplatin administration. However, the underlying mechanism of BAG1-regulated ER stress and apoptosis remains to be clarified.

It should be noted that, in the present study, low-dose cisplatin treatment $(1.25 \mu \mathrm{g} / \mathrm{ml})$ dramatically upregulated the level of BAG1 protein, while at higher concentrations ( 2.5 or $5 \mu \mathrm{g} / \mathrm{ml}$ ) BAG1 levels increased only marginally. This suggests that low concentrations of cisplatin may promote BAG1 levels and thus enhance its antiapoptotic activity (8). Accordingly, the percentage of apoptotic cells gradually increased with the increase of cisplatin dose.

Collectively, the results demonstrate that BAG1 is involved in the response to platinum-based chemotherapy in NSCLC patients and in cultured human lung adenocarcinoma A549 cells. These findings may provide valuable insights into how genetic variations influence sensitivity to chemotherapy in NSCLC patients, as well as evidence of the involvement of ER stress in cisplatin-induced tumor cell death.

In conclusion, the results indicate that BAG1 plays a positive role in cisplatin-induced cell death in lung adenocarcinoma, suggesting that ER stress may promote sensitivity to chemotherapy in NSCLC patients. 


\section{Acknowledgements}

This study was supported by Liaoning Provincial Health Department Medical Peak Construction.

\section{References}

1. Siegel R, Ward E, Brawley O and Jemal A: Cancer statistics, 2011 The impact of eliminating socioeconomic and racial disparities on premature cancer deaths. CA Cancer J Clin 61: 212-236, 2011

2. Bareschino MA, Schettino C, Rossi A, Maione P, Sacco PC, Zeppa R and Gridelli C: Treatment of advanced non small cell lung cancer. J Thorac Dis 3: 122-133, 2011.

3. Zeng H, Zheng R, Guo Y, Zhang S, Zou X, Wang N, Zhang L, Tang J, Chen J, Wei K, et al: Cancer survival in China, 20032005: A population-based study. Int J Cancer 136: 1921-1930, 2015.

4. Waters JS and O'Brien ME: The case for the introduction of new chemotherapy agents in the treatment of advanced non small cell lung cancer in the wake of the findings of the national institute of clinical excellence (NICE). Br J Cancer 87: 481-490, 2002.

5. Fernet $\mathrm{M}$ and Hall J: Genetic biomarkers of therapeutic radiation sensitivity. DNA Repair (Amst) 3: 1237-1243, 2004.

6. Ulrich CM, Robien K and McLeod HL: Cancer pharmacogenetics: Polymorphisms, pathways and beyond. Nat Rev Cancer 3 : 912-920, 2003.

7. Townsend PA, Cutress RI, Sharp A, Brimmell M and Packham G BAG-1: A multifunctional regulator of cell growth and survival. Biochim Biophys Acta 1603: 83-98, 2003.

8. Takayama S, Sato T, Krajewski S, Kochel K, Irie S, Millan JA and Reed JC: Cloning and functional analysis of BAG-1G1: A novel Bcl-2-binding protein with anti-cell death activity. Cell 80 279-284, 1995

9. Townsend PA, Stephanou A, Packham G and Latchman DS BAG-1G1: A multi-functional pro-survival molecule. Int J Biochem Cell Biol 37: 251-259, 2005.

10. Yang L, McBurney D, Tang SC, Carlson SG and Horton WE Jr: A novel role for Bcl-2 associated-athanogene-1 (Bag-1) in regulation of the endoplasmic reticulum stress response in mammalian chondrocytes. J Cell Biochem 102: 786-800, 2007.

11. Rorke S, Murphy S, Khalifa M, Chernenko G and Tang SC: Prognostic significance of BAG-1 expression in nonsmall cell lung cancer. Int J Cancer 95: 317-322, 2001.

12. Liu H, Bai Y, Liu B, Wang Z, Wang M, Zhou Q and Chen J: The expression of BAG-1 and its clinical significance in human lung cancer. Zhongguo Fei Ai Za Zhi 11: 489-494, 2008 (In Chinese).

13. Gotz R, Kramer BW, Camarero G and Rapp UR: BAG-1 haplo-insufficiency impairs lung tumorigenesis. BMC Cancer 4 85, 2004.

14. Greene FL, Page DL, Fritz AG, et al (eds): Lung. In: AJCC Cancer Staging Manual. 6th edition. Springer, New York, NY, pp170-171, 2001.

15. Karnofsky DA and Burchenal JH: The clinical evaluation of chemotherapeutic agents in cancer. In: Evaluation of Chemotherapeutic Agents. MacLeod CM (ed). Columbia University Press, New York, NY, pp191-205, 1949.
16. Therasse P, Arbuck SG, Eisenhauer EA, Wanders J, Kaplan RS, Rubinstein L, Verweij J, Van Glabbeke M, van Oosterom AT, Christian MC and Gwyther SG: New guidelines to evaluate the response to treatment in solid tumors. European organization for research and treatment of cancer, national cancer institute of the United States, national cancer institute of Canada. J Natl Cancer Inst 92: 205-216, 2000.

17. Lowry OH, Rosebrough NJ, Farr AL and Randall RJ: Protein measurement with the Folin phenol reagent. J Biol Chem 193 265-275, 1951.

18. Xu C, Bailly-Maitre B and Reed JC: Endoplasmic reticulum stress: Cell life and death decisions. J Clin Invest 115: 2656-2664, 2005.

19. Nakagawa T, Zhu H, Morishima N, Li E, Xu J, Yankner BA and Yuan J: Caspase-12 mediates endoplasmic-reticulum-specific apoptosis and cytotoxicity by amyloid-beta. Nature 403: 98-103, 2000.

20. Schiller JH, Harrington D, Belani CP, Langer C, Sandler A, Krook J, Zhu J and Johnson DH; Eastern Cooperative Oncology Group: Comparison of four chemotherapy regimens for advanced non-small-cell lung cancer. N Engl J Med 346: 92-98, 2002.

21. Gurubhagavatula S, Liu G, Park S, Zhou W, Su L, Wain JC, Lynch TJ, Neuberg DS and Christiani DC: XPD and XRCC1 genetic polymorphisms are prognostic factors in advanced non-small-cell lung cancer patients treated with platinum chemotherapy. J Clin Oncol 22: 2594-2601, 2004.

22. Booton R, Ward T, Heighway J, Taylor P, Power F, Ashcroft L, Morris $\mathrm{J}$ and Thatcher N: Xeroderma pigmentosum group D haplotype predicts for response, survival and toxicity after platinum-based chemotherapy in advanced nonsmall cell lung cancer. Cancer 106: 2421-2427, 2006.

23. Kim SH, Juhnn YS and Song YS: Akt involvement in paclitaxel chemoresistance of human ovarian cancer cells. Ann NY Acad Sci 1095: 82-89, 2007

24. Matakidou A, el Galta R, Webb EL, Rudd MF, Bridle H, GELCAPS Consortium, Eisen T and Houlston RS: Genetic variation in the DNA repair genes is predictive of outcome in lung cancer. Hum Mol Genet 16: 2333-2340, 2007.

25. Wu X, Lu C, Ye Y, Chang J, Yang H, Lin J, Gu J, Hong WK, Stewart D and Spitz MR: Germline genetic variations in drug action pathways predict clinical outcomes in advanced lung cancer treated with platinum-based chemotherapy. Pharmacogenet Genomics 18: 955-965, 2008

26. Liu H, Bai Y, Liu B, Wang Z, Wang M, Zhou Q and Chen J: The expression of BAG-1 and its clinical significance in human lung cancer. Zhongguo Fei Ai Za Zhi 11: 489-494, 2008.

27. Morishima N, Nakanishi K, Takenouchi H, Shibata T and Yasuhiko Y: An endoplasmic reticulum stress-specific caspase cascade in apoptosis. Cytochrome c-independent activation of caspase-9 by caspase-12. J Biol Chem 277: 34287-34294, 2002.

28. Tan Y, Dourdin N, Wu C, De Veyra T, Elce JS and Greer PA: Ubiquitous calpains promote caspase-12 and JNK activation during endoplasmic reticulum stress-induced apoptosis. J Biol Chem 281: 16016-16024, 2006. 